\title{
TINGKAT REFLEKSI DIRI DALAM PEMBELAJARAN PESERTA UJI KOMPETENS MAHASISWA PROGRAM PROFESI DOKTER FAKULTAS KEDOKTERAN UNIVERSITAS MALAHAYATI
}

\author{
Wildan Khaerul Umam ${ }^{1}$, Sri Maria Puji Lestari ${ }^{2}$, Tusy Triwahyuni ${ }^{3}$, Octa Reni \\ Setiawati ${ }^{4}$ \\ ${ }^{1}$ Mahasiswa Fakultas Kedokteran Universitas Malahayati \\ 2,3,4Dosen Fakultas Kedokteran Universitas Malahayati \\ Email : wildankhaerul97@gmail.com
}

\section{ABSTRACT: LEVEL OF SELF REFLECTION IN LEARNING PARTICIPANT COMPENTENCY EXAMINATION FACULTY OF MEDICINE MALAHAYATI UNIVERSITY}

Background: Self reflection has benefits in enhancing learning and selfdevelopment so that it can make reflection as a learning tool that may be implemented at various levels of education.

Objectives: Knowing the level of self-reflection of students at the Faculty of Medicine, Malahayati University.

Methods: This is a descriptive quantitative study with a cross sectional approach. The population used in this study were participants in the student competency test of the medical profession program, Faculty of Medicine, University of Malahayati. The population in this study was 110 respondents. The data analysis technique used the percentage test.

Results: of the study obtained 87 respondents mostly have a low level of reflection, namely as many as 71 respondents (81.6\%), medium reflection rate of 15 respondents $(17.2 \%)$ and high reflection rate of 1 respondent $(1.1 \%)$.

Conclusion: It is hoped that students can maintain and increase self-reflection in learning in order to improve their ability to learn to achieve maximum learning outcomes.

Keywords: Self-Reflection Level, Medical Students

\section{INTISARI: TINGKAT REFLEKSI DIRI DALAM PEMBELAJARAN PESERTA UJI KOMPETENSI MAHASISWA PROGRAM PROFESI DOKTER FAKULTAS KEDOKTERAN UNIVERSITAS MALAHAYATI TAHUN 2020}

Latar Belakang :refleksi diri memiliki manfaat untuk meningkatkan pembelajaran dan pengembangan diri sehingga dapat menjadikan refleksi tersebut sebagai alat pembelajaran yang mungkin diimplementasikan pada berbagai level pendidikan.

Tujuan penelitian: mengetahui tingkat refleksi diri peserta UKMPPD Fakultas Kedokteran Universitas Malahayati.

Metode Penelitian : Jenis penelitian deskriptif kuantitatif dengan pendekatan cross sectional. Populasi yang digunakan dalam penelitian ini adalah peserta uji kompetensi mahasiswa program profesi dokter Fakultas Kedokteran Universitas Malahayati. Jumlah populasi pada penelitian ini adalah 110 responden.Teknik analisis data menggunakan uji persentase. 
Hasil penelitian Didapatkan 87 responden sebagian besar memiliki tingkat refleksi rendah yaitu sebanyak 71 responden $(81,6 \%)$,tingkat refleksi sedang 15 responden (17.2\%) dan tingkat refleksi tinggi 1 responden $(1.1 \%)$.

Kesimpulan Diharapkan mahasiswa dapat mempertahankan dan meningkatkan refleksi diri dalam pembelajaran guna meningkatkan kemampuan dalam belajar untuk mencapai hasil belajar yang maksimal.

Kata Kunci : Tingkat Refleksi Diri, Mahasiswa Kedokteran

\section{PENDAHULUAN}

Refleksi berasal dari bahasa latin yang berarti "to bend" atau "to turn back". Refleksi dalam konteks pendidikan dapat disadari sebagai proses atau tindakan untuk melihat kembali ke masa lampau dengan tujuan untuk memproses pengalaman yang didapat sehingga dapat diinterpretasi atau dilakukan analisis. Refleksi merupakan suatu proses metakognitif yang terjadi sebelum, selama dan sesudah situasi tertentu dengan tujuan untuk mengembangkan pemahaman yang lebih baik mengenai diri sendiri dan situasi yang dihadapi sehingga ketika di masa depan menemui situasi serupa dapat bertindak lebih baik (Sandars J, 2009).

Proses dari refleksi memiliki manfaat dalam meningkatkan pembelajaran dan pengembangan diri sehingga dapat menjadikan refleksi tersebut sebagai alat pembelajaran yang mungkin diimplementasikan pada berbagai level pendidikan (Kanthan \& Senger, 2011). Oleh karena itu, tingkat pengetahuan mahasiswa terhadap refleksi diri bagi mahasiswa sangat penting dalam menjalani setiap kegiatan pembelajaran sehingga diharapkan memiliki pengaruh positif bagi hasil prestasi belajar.

Salah satu kompetensi yang diharapkan ada pada lulusan dokter menurut Standar Kompetensi Dokter Indonesia (SKDI) 2012 adalah mampu mempraktikkan belajar sepanjang hayat dengan menyadari kinerja profesionalitas diri dan mengidentifikasi kebutuhan belajar untuk mengatasi kelemahan. Oleh karena itu, mahasiswa kedokteran harus dilatih untuk dapat melakukan refleksi diri terhadap proses belajar, pengalaman dan pencapaiannya untuk dapat mengetahui kelemahan dan kekuatan dirinya, dan kemudian menyusun sebuah rencana tindak lanjut yang sesuai dengan tujuan untuk dapat memperbaiki kekurangan dan meningkatkan kemampuan diri. Kemampuan ini diharapkan akan terbawa menjadi sikap sehari-hari setelah lulus dari proses pendidikan dokter, agar dapat terus melakukan proses belajar sepanjang hayat walau sudah tidak menjalani pendidikan formal. (Oktaria, 2015)

Prestasi belajar merupakan tingkat pencapaian yang dimiliki mahasiswa dalam menerima, menolak dan menilai informasiinformasi yang diperoleh dalam proses belajar mengajar. Prestasi belajar seseorang sesuai dengan tingkat keberhasilannya dalam mempelajari materi pelajaran dan nantinya akan dinyatakan dalam bentuk nilai (Hamdu \& Agustina, 2011).

Pembelajaran harus dirancang sedemikian rupa agar pelajar dapat memahami materi yang disampaikan oleh pengajar dengan jelas yang tentu saja akan berpengaruh pada hasil yang akan didapat oleh pelajar tersebut. Pembelajaran adalah suatu kombinasi yang tersusun dari unsurunsur manusiawi, material, fasilitas, perlengkapan dan prosedur yang saling mempengaruhi untuk mencapai tujuan pembelajaran (Hamalik, 2008). 
Faktor-faktor yang mempengaruhi belajar seseorang dapat dibedakan menjadi dua macam yakni faktor internal merupakan keadaan atau kondisi jasmani dan rohani yang juga meliputi aspek psikologis seperti intelegensi, sikap, bakat, minat dan motivasi serta meliputi juga aspek panca indera seseorang. Faktor eksternal yaitu kondisi lingkungan disekitarnya meliputi lingkungan sosial seseorang dan lingkungan non sosial meliputi rumah, gedung sekolah dan sebagainya (Muhibbin, 2010).

Faktor pendekatan belajar (approach to learning) yaitu upaya belajar peserta meliputi strategi dan metode yang digunakan untuk melakukan kegiatan pembelajaran. Dengan strategi memperhatikan dengan baik dosen yang sedang menjelaskan materi kuliah dan metode mengulang materi yang telah diajarkan dengan cara diskusi kelompok kecil dengan teman.

Prestasi belajar dalam ujian UKMPPD berbentuk nilai sesuai UU No. 29 Tahun 2004 tentang Praktik Kedokteran, mahasiswa yang telah menyelesaikan tahap Pendidikan Profesi Dokter harus mengikuti Uji Kompetensi Mahasiswa Program Profesi Dokter. UKMPPD telah dilaksanakan sejak tahun 2007, yang sebelumnya bernama UKDI. Komite Dokter Indonesia, Asosiasi Institusi Pendidikan Kedokteran Indonesia, Perhimpunan Dokter Keluarga Indonesia dan sejumlah perangkat lainnya telah menyepakati UKMPPD sebagai sertifikasi dokter lulusan baru Fakultas Kedokteran dengan mengacu pada Standar Kompetensi Dokter Indonesia (SKDI) yang disahkan oleh Komisi Kedokteran Indonesia (KKI) (PNUKMPPD, 2015).

Menurut penelitian sebelumnya yang dilakukan oleh Rani Tiara Universitas Lampung pada tahun 2017 hasil penelitian menunjukkan terdapat $159 \quad(74,6 \%)$ mahasiswa dengan tingkat refleksi diri sedang, 28
$(13,1 \%)$ mahasiswa memiliki tingkat refleksi diri tinggi dan 26 (12,2\%) mahasiswa lainnya berada dalam tingkat refleksi diri rendah.

Berdasarkan dari uraian diatas serta tidak ada penelitian sebelumnya mengenai tingkat refleksi diri dalam pembelajaran peserta Uji Kompetensi Mahasiswa Program Profesi Dokter di Universitas Malahayati maka saya tertarik melakukan penelitian dengan tema tersebut.

\section{METODE PENELITIAN}

Desain penelitian yang digunakan pada penelitian ini bersifat deskriptif kuantitatif dengan pendekatan cross sectional yang digunakan dalam satu waktu. Adapun sumber data yang digunakan dalam penelitian adalah data primer yang diambil dari kuesioner. Penelitian ini dilaksanakan pada bulan November 2020 sampai dengan Desember 2020. Penelitian ini dilaksanakan di Fakultas Kedokteran Universitas Malahayati. Populasi pada penelitian ini adalah peserta uji kompetensi mahasiswa program profesi dokter Fakultas Kedokteran Universitas Malahayati. Jumlah populasi pada penelitian ini adalah 110 responden. Sampel 87 sampel. Pada penelitian ini terdapat satu variabel yaitu refleksi diri pada peserta UKMPPD Universitas Malahayati tahun 2019. Alat yang digunakan dalam penelitian ini adalah alat tulis dan lembar kuesioner. Kuesioner yang digunakan dalam penelitian ini adalah kuesioner untuk mengukur tingkat refleksi yang telah dimodifikasi dari kuesioner Metacognitive Awareness Inventory (MAI). Kuesioner terdiri atas 38 pertanyaan serta telah dilakukan uji validitas dan reabilitas diperoleh nilai Cronbach's Alpha 0,937 sehingga didapatkan 34 pertanyaan yang valid dari 38 pertanyaan sebelum dilakukan uji validitas. Sehingga dapat disimpulkan pertanyaan reliable 
dapat digunakan sebagai alat ukur. Pada penelitian ini, data yang dikumpulkan adalah data primer. Jenis data ini diperoleh secara langsung dari subjek penelitian. Data primer diperoleh dengan membagikan kuesioner pada sampel penelitian yaitu mahasiswa UKMPPD Universitas Malahayati tahun2020. Sebelum responden melakukan pengisian kuesioner, responden terlebih dahulu diberikan penjelasan sehingga responden benar-benar jelas dan mengerti. Analisis univariat bertujuan untuk menjelaskan atau mendeskripsikan karakteristik tiap variabel penelitian. Bentuk analisis univariat tergantung dari jenis datanya. Pada umumnya dalam analisis ini hanya menghasilkan distribusi frekuensi dan persentase dari tiap variabel (Notoatmodjo, 2012).

\section{HASIL PENELITIAN}

Penelitian dilaksanakan pada bulan November-Desember 2020, pengambilan data selama 2 minggu dengan menggunakan data primer, dengan sampel yang digunakan sebanyak 87 responden peserta uji kompetensi program profesi dokter fakultas kedokteran Universitas Malahayati 2020 yang merupakan mahasiswa fakultas kedokteran Universitas Malahayati angkatan 2014 pada batch November dan peserta First Taker 69 mahasiswa (79.3\%) dan Retaker 18 mahasiswa (20.7\%). Setelah dilakukan pengumpulan dan pengolahan data serta analisis data responden menggunakan program excel. Analisis statistik yang dilakukan adalah perhitungan sebaran frekuensi.
Karakteristik Responden

Tabel 1 Distribusi Frekuensi berdasarkan Jenis Kelamin dan Usia peserta uji kompetensi program profesi dokter fakultas kedokteran Universitas Malahayati 2020

\begin{tabular}{lcc}
\hline $\begin{array}{c}\text { Jenis } \\
\text { Kelamin }\end{array}$ & Jumlah & Persentase \\
\hline Laki-laki & 43 & 49.4 \\
Perempuan & 44 & 50.6 \\
\hline Umur & Jumlah & Persentase \\
\hline$\leq 25$ Tahun & 64 & 73.5 \\
$>25$ Tahun & 23 & 26.5 \\
\hline Jumlah & 87 & 100.0 \\
\hline
\end{tabular}

Berdasarkan Tabel 1 diketahui bahwa sebagian besar responden berjenis kelamin perempuan yaitu sebanyak 44 responden $(50,6 \%)$, sedangkan responden yang berjenis kelamin lakilaki sebanyak 43 responden $(49,4 \%)$. Sebagian besar responden berusia $\leq$ 25 tahun yaitu sebanyak 64 responden $(73,5 \%)$.

Tingkat Refleksi Diri

Tabel 2. Distribusi Frekuensi berdasarkan Tingkat Refleksi Diri peserta uji kompetensi program profesi dokter fakultas kedokteran Universitas Malahayati 2020

\begin{tabular}{lcc}
\hline $\begin{array}{c}\text { Tingkat } \\
\text { Refleksi } \\
\text { Diri }\end{array}$ & Jumlah & Persentase \\
\hline Rendah & $\mathbf{7 1}$ & $\mathbf{8 1 . 6}$ \\
Sedang & 15 & 17.2 \\
Tinggi & 1 & 1.1 \\
\hline Jumlah & 60 & 100.0 \\
\hline
\end{tabular}

Berdasarkan tabel 2 diketahui bahwa sebagian besar responden memiliki tingkat refleksi rendah yaitu sebanyak 71 responden $(81,6 \%)$ adapun hasil analisis terhadap pertanyaan diperoleh: 
Tabel 3. Analisis Butir Soal berdasarkan Jawaban Tertinggi dan Terendah

\begin{tabular}{|c|c|c|}
\hline No & Pernyataan & Skor \\
\hline \multicolumn{3}{|c|}{ Tertinggi } \\
\hline 26 & $\begin{array}{l}\text { Saya mempunyai tujuan khusus pada setiap strategi } \\
\text { belajar yang saya gunakan. }\end{array}$ & 358 \\
\hline 30 & $\begin{array}{l}\text { Saya memikirkan beberapa cara untuk } \\
\text { menyelesaikan masalah dan memilih yang terbaik. }\end{array}$ & 358 \\
\hline 9 & $\begin{array}{l}\text { Saya dapat menilai dengan baik sejauh mana saya } \\
\text { memahami sesuatu yang sudah saya pelajari } \\
\text { sebelumnya. }\end{array}$ & 361 \\
\hline 31 & $\begin{array}{l}\text { Ketika saya mengalami kesulitan saya dapat } \\
\text { memotivasi diri saya. }\end{array}$ & 361 \\
\hline 1 & $\begin{array}{l}\text { Pada waktu tertentu saya mempelajari ulang } \\
\text { untuk membantu dalam memahami materi yang } \\
\text { saling berhubungan }\end{array}$ & 376 \\
\hline \multicolumn{3}{|c|}{ Terendah } \\
\hline 5 & $\begin{array}{l}\text { Saya bertanya kepada diri saya apakah ada acara } \\
\text { yang lebih mudah dalam mengerjakan suatu tugas, } \\
\text { sesaat setelah saya menyelesaikannya }\end{array}$ & 179 \\
\hline 4 & $\begin{array}{l}\text { Saya menggunakan strategi belajar yang sama, } \\
\text { walaupun pada situasi yang berbeda. }\end{array}$ & 191 \\
\hline 6 & $\begin{array}{l}\text { Saya mengalami kebingungan terhadap harapan } \\
\text { dosen tentang pelajaran yang telah dipelajari }\end{array}$ & 229 \\
\hline 14 & $\begin{array}{l}\text { Saya tidak dapat memfokuskan materi/perhatian } \\
\text { pada informasi penting. }\end{array}$ & 230 \\
\hline 11 & $\begin{array}{l}\text { Saya kurang memahami kekuatan dan kelemahan } \\
\text { diri saya dalam melakukan kegiatan pembelajaran }\end{array}$ & 237 \\
\hline
\end{tabular}

Berdasarkan tabel 3. kuesioner yang memiliki nilai tertinggi adalah pertanyaan no 1 berisi pertanyaan "Pada waktu tertentu saya mempelajari ulang untuk membantu dalam memahami materi yang saling berhubungan." dengan skor nilai 376, sedangkan yang paling rendah adalah

\section{PEMBAHASAN}

Hasil penelitian menunjukkan bahwa sebagian besar responden berjenis kelamin perempuan yaitu sebanyak 44 responden (50,6\%). Jumlah mahasiswa perempuan lebih banyak karena jumlah mahasiswa perempuan lebih banyak ditambah lagi sebagian besar yang bersedia berpartisipasi lebih banyak perempuan (Ritunga, Rahayu \& pertanyaan no 5 berisi pertanyaan "Saya bertanya kepada diri saya apakah ada acara yang lebih mudah dalam mengerjakan suatu tugas, sesaat setelah saya menyelesaikannya" dengan skor nilai 179.

Suhoyo, 2018). Hasil penelitian ini sejalan dengan beberapa penelitian yang menunjukkan hasil bahwa perempuan lebih banyak dari pada jumlah laki-laki salahsatunya penelitia Imelda tahun 2018.

Responden berusia $\leq 25$ tahun yaitu sebanyak 64 responden $(73,5 \%)$. Hal ini disebabkan karena mereka telah menyelesaikan pendidikan kedokteran pada usia $\leq 25$ tahun. 
Hasil penelitian menunjukkan bahwa sebagian besar responden memiliki tingkat refleksi rendah yaitu sebanyak 71 responden $(81,6 \%)$. Refleksi diri menjembatani mahasiswa untuk menghubungkan teori yang mereka dapat selama pendidikan sarjana dengan praktik klinik yang sesungguhnya, dan oleh karenanya memfasilitasi proses refleksi sangat penting untuk proses belajar mahasiswa. Hal yang sangat penting dalam pendidikan klinik adalah proses memperkuat hubungan antara pengalaman belajar dan aktivitas refleksi terhadap pengalaman tersebut. Pengalaman tanpa adanya proses pemaknaan akan menjadikan pengalaman tersebut bukan sebuah pembelajaran (Susani, 2009). Oleh karena itu refleksi bagi mahasiswa kedokteran sangatlah penting dalam proses pembelajaran karena dapat memberikan hal baik terhadap perencanaaan studi dan terhadap prestasi belajar.

Refleksi berasal dari Bahasa Latin yang berarti "to bend" atau "to turn back". Dalam konteks pendidikan dapat disadari sebagai proses atau tindakan untuk melihat kembali ke masa lampau dengan tujuan untuk memproses pengalaman yang didapat sehingga dapat diinterpretasikan atau dilakukan analisis (Oktaria, 2015). Refleksi diri dapat membantu mahasiswa menyadari apa yang telah mereka kerjakan atau yang tidak dikerjakan selama kegiatan yang mereka ikuti dan memungkinkan mereka membuat penyesuaian atau mengubah apa yang akan dilakukan sesuai dengan kebutuhan berdasarkan hasil refleksi (Shafira, 2015).

Berdasarkan hasil penelitian yang dilakukan oleh Rani Tiara mahasiswi Universitas Lampung pada tahun 2017 hasil penelitian menunjukan terdapat 159 (74,6\%) mahasiswa dengan tingkat refleksi diri sedang, 28 $(13,1 \%)$ mahasiswa memiliki tingkat refleksi diri tinggi dan 26 (12,2\%) mahasiswa lainnya berada dalam tingkat refleksi diri rendah.

Proses dari refleksi memiliki manfaat dalam meningkatkan pembelajaran dan pengembangan diri sehingga dapat menjadikan refleksi tersebut sebagai alat pembelajaran yang mungkin diimplementasikan pada berbagai level pendidikan (Kanthan \& Senger, 2011). Oleh karena itu, tingkat pengetahuan mahasiswa terhadap refleksi diri bagi mahasiswa sangat penting dalam menjalani setiap kegiatan pembelajaran sehingga diharapkan memiliki pengaruh positif bagi hasil prestasi belajar.

Dalam penelitian ini diketahui bahwa sebagian besar responden memiliki tingkat refleksi rendah yaitu sebanyak 39 responden $(65,0 \%)$. Hal ini dapat disebabkan karena faktor kebersamaan, dimana sebagian besar mahasiwa tingga bersama dalam asrama. Sebagai makhluk sosial, unsur kebersamaan dan bermasyarakat harus ada dan tertanam pada setiap individu. Dalam upaya pembentukan kesadaran diri, unsur kebersamaan dengan membangun relasi yang baik dengan diri sendiri. Didalam kebersamaan yang dilakukan oleh pribadi, didapatkan dua buah unsur pembentuk kesadaran diri berupa : penilaian orang lain terhadap diri (kelebihan dan kekurangan diri) dan keteladanan dari orang lain. Unsur interaksi sosial yang terjalin di masyarakat dan penilaian orang lain terhadap diri sangat mempengaruhi pembentukan kesadaran diri pada manusia.

Selain itu faktor kecerdasan, karena untuk menjadi mahasiswa kedokteran seseorang diperlukan untuk dapat lulus seleksi berupa ujian, sehingga mereka yang saat ini menjadi mahasiswa fakultas kedokteran memiliki kecerdasan yang baik. Dalam upaya pembentukan pribadi yang berkualitas, terdapat 
landasan diri yang harus dilalui oleh manusia untuk mencapai esensi ketahanan pribadi atau karakter yangkuat yaitu kecerdasan hidup. Indikasi adanya kecerdasan hidup pada diri manusia itu berupa : rasa percaya diri dalam memegang prinsip hidup yang diiringi dengan kemandirian yang kuat dan mempunyai visi untuk lebih mengedepankan kepentingan umum daripada kepentingan pribadi. Unsur kebersamaan dan kecerdasan yang terdapat dalam faktor cara pandang (anittude) menumbuhkan sebuah gambaran diri yang baik dalam tatanan sosial (kemasyarakatan). Dari sikap pandang baik yang terdapat dalam diri manusia maka masyarakat akan melihat diri sebagai sosok pribadi yang dapat menjalankan fungsi sebenarnya dari hakikat penciptaan manusia di bumi, yaitu makhluk sosial yang memiliki akal budi, naluri dan intuisi yang khas. Mahasiswa

Fakultas

Kedokteran Universitas Malahayati yang menjadi responden adalah mahasiswa yang menghadapi ujian UKMPPD batch November. Sejalan dengan penelitian Oktaria pada tahun 2015 menyebutkan konsep pengajaran dan pembelajaran melalui refleksi diri perlu diintegrasikan pada pendidikan tahap preklinik secara lebih luas. Mahasiswa perlu dibekali dengan konsep yang jelas mengenai refleksi diri dan manfaatnya serta diberikan panduan dan aturan dalam melakukan proses refleksi diri. Melalui proses pembelajaran refleksi diri, diharapkan mahasiswa dapat menjadi pembelajar sepanjang hayat yang reflektif (Oktaria, 2015). Oleh karena itu sesuai dengan hasil penelitian, karena masih terdapat tingkat refleksi diri yang rendah perlu menjadi evalusai terkait pemaparan teori refleksi diri pada mahasiswa tahap sarjana dan evaluasi untuk penerapannya, hingga mahasiswa dapat memahami apa itu refleksi diri, pentingnya dan dapat terbiasa menerapkan disepanjang proses pendidikannya. Mahasiswa harus senantiasa meningkatkan pemahaman dan kemampuan refleksi diri dalam setiap kegiatan pembelajaran pada diri sendiri untuk persiapan menempuh langkah selanjutnya yaitu pendidikan profesi dokter

\section{KESIMPULAN}

1. Hasil penelitian menunjukkan bahwa sebagian besar responden berjenis kelamin perempuan yaitu sebanyak 44 responden $(50,6 \%)$, sedangkan responden yang berjenis kelamin laki-laki sebanyak 43 responden $(49,4 \%)$

2. Hasil penelitian menunjukkan bahwa sebagian besar responden berusia $\leq 25$ tahun yaitu sebanyak 64 responden (73,5\%).dan sebagian besar responden memiliki tingkat refleksi rendah yaitu sebanyak 71 responden $(81,6 \%)$.

\section{Saran}

Peneliti menyarankan refleksi diri mahasiswa terus dilakukan evaluasi oleh para fasilitator (dosen) tidak hanya di tahun kedua tetapi juga pada tahun pertama, ketiga dan keempat agar dapat meningkatkan kualitas belajar dari mahasiswa dalam menempuh proses pendidikan kedokteran. Proses releksi yang dapat dilakukan dengan reflection in action dan reflection on action. 


\section{DAFTAR PUSTAKA}

Alseny, S. \& Al Saif, A. (2012). Developing Skills In Managing Objective Structured Clinical Examina ons (OSCE), Life Science Journal, 9(3), 597-602.

Boud D, dkk. (1985). Reflection: turning experience into learning. London: Kogan Page.

Dahlan, Ahmad. (2014). Populasi dan Sampel Penelitian. http://www.eurekapendidika n.com diakses pada 11 Maret 2019.

Divisi Ujian Uji Kompetensi Dokter Indonesia. (2011). Petunjuk Pembuatan Soal. http://www.ukdi.org diakses pada 12 Desember 2018.

Glen, P. M. (2011). Assessing Resident Communications Skills: Disclosure of an Adverse Event to a Standardized Patient. J Obstet Gynaecol Can, 33(3), 262.

Hamdu, G., Agustina, L. (2011). Pengaruh Motivasi Belajar Siswa Terhadap Prestasi Belajar IPA Di Sekolah Dasar (Studi Kasus Terhadap Siswa Kelas IV SDN Tarumanegara Kecamatan Tawang Kota Tasikmalaya). Jurnal Penelitian Pendidikan, 12(1), 81-6.

Hamalik, Oemar. (2008). Kurikulum dan Pembelajaran . Jakarta: SinarGrafika.

IDI. (2007). Uji Kompetensi Dokter Indonesia. Jakarta. Ikatan Dokter Indonesia. http://www.idionline.org diakses pada 10 November 2018.

Khan \& Ramachandran. (2012). The Objective Structured Clinical Examination (OSCE): AMEE Guide No.81, Part 1: an historical and theoretical perspective.
Notoatmodjo, P. (2012). Metodologi Penelitian Kesehatan. Jakarta: Rineka Cipta.

Phan, H. P. (2008). Achievement Goals, The Classroom Environtment, and Reflective Thinking: $A$ Conceptual Framework, dalam Electronic Journal of Research in Education Psychology, 6(3), 578.

PNUKMPPD. (2015). Panduan Uji Kompetensi Mahasiswa Program Profesi Dokter (UKMPPD).

Sandars, J. (2009). The use of reflections in medical education: AMEE Guide No. 44. Med Teach, 31(18), 685-95.

Sastroasmoro, S., Sofyan, I. (2014). Dasar-Dasar Metodologi Penelitian Klinis, Edisi ke-5. Jakarta: CV. Sagung Seto. P.130-7, 352-17.

Schon, D. A. (1983). The Reflective Practitioner. How Professional Think in Action. London, Temple Smith.

Sherbino, J., dkk. (2008). Assessing Competence In Emergency Medicine Trainees: an Overview of Effective Methodologies.CJEM, 10(4), 365-71.

Shafira, N. N. (2015). Penerapan Refleksi Diri dan Self Evaluation Sebagai Keterampilan Dasar Dalam Meningkatkan Profesionalisme Pada Mahasiswa Kedokteran. JMJ, Volume 3, Nomor 1, 64.

Susani, Y. P. (2009). Refleksi dalam Pendidikan Klinik. Jurnal Pendidikan Kedokteran dan Profesi Kesehatan Indonesia, Vol. 4, No. 1, 1.

Syah, Muhibbin. (2010). Psikologi Pendidikan. Bandung: Remaja Rosdakarya. 